\title{
FATIGUE ANALYSIS OF COMPOSITE HIGHWAY BRIDGE DECKS
}

\author{
F. N. Leitão ${ }^{1}$, J. G. S. da Silva ${ }^{2}$, S. A. L. de Andrade ${ }^{3}$
}

${ }^{1}$ Civil Engineering Post-graduate Program, PGECIV, State University of Rio de Janeiro, UERJ (fernando_nahid@hotmail.com)

${ }^{2}$ Structural Engineering Department, State University of Rio de Janeiro, UERJ

${ }^{3}$ Civil Engineering Department, Pontifical Catholic University of Rio de Janeiro, PUC-Rio

\begin{abstract}
Steel and composite (steel-concrete) highway bridges are usually subjected to dynamic actions of variable magnitude due to vehicles crossing on the deck pavement. These dynamic actions can generate the nucleation of fractures or even their propagation on the bridge structure. Depending on the magnitude and intensity of these actions, these effects may compromise the structural system response reliability that could also lead to a reduction of the expected bridge service life. Therefore, this investigation aims to develop an analysis with emphasis to evaluate the stresses through a dynamic analysis of composite highway bridge decks including the action of convoy of heavy vehicles. The investigated highway bridge is constituted by four longitudinal composite girders and a concrete deck, spanning 40m. The developed computational model adopted the usual mesh refinement techniques present in finite element method simulations implemented in the ANSYS program. The analysis methodology and procedures presented in the design codes were applied to evaluate the fatigue of the bridge determining the service life of the structure. The main conclusions of this investigation focused on alerting structural engineers to the possible distortions, associated to the steel and composite bridge's service life when subjected to vehicle's dynamic actions.
\end{abstract}

Keywords: Fatigue assessment, Structural dynamics, Composite highway bridge decks.

\section{INTRODUCTION}

Steel and composite (steel-concrete) highway bridges are usually subjected to dynamic actions of variable magnitude due to convoy of vehicles crossing on the deck pavement. Depending on the magnitude and intensity of these dynamic actions, these adverse effects may compromise the structural system response reliability that could also lead to a reduction of the expected bridge service life [1-3]. Proper consideration of all of the aspects earlier mentioned pointed our team to develop an analysis methodology with emphasis to evaluate the stresses through a dynamic analysis of steel and composite (steel-concrete) highway bridge decks, including the action of vehicles crossing on the pavement surface [1-4]. 
The present investigation utilizes techniques for counting stress-cycles and for applying cumulative damage rules combined with S-N curves. The first steps of the composite highway bridge study involved an extensive literature review of the techniques used to define steel and composite bridges service life, a study of the theoretical aspects of fatigue in steel, and the recommended procedures present in main steel and composite (steel-concrete) structural design codes $[5,6]$.

The design codes recommend the adoption of the S-N curves associated with the Miner's damage rule to evaluate the steel and composite bridges fatigue and service life. These codes also recommend that the bridge structure designs should avoid local stress concentrations, to prevent possible fatigue points.

The investigated composite bridge has a roadway width of $12.50 \mathrm{~m}$ and a concrete deck thickness of $0.23 \mathrm{~m}$, spanning $40.0 \mathrm{~m}$ by $13.5 \mathrm{~m}$. The structural system consists of four longitudinal composite girders and a concrete deck. The computational model used in the composite bridge dynamic analysis, adopts the usual mesh refinement techniques present in finite element method simulations implemented in the ANSYS program [7].

The beam steel sections were simulated by three-dimensional beam and shell finite elements. The beam web was represented by shell finite elements. The top and bottom beam flanges and the longitudinal and vertical stiffeners were simulated by three-dimensional beam elements considering flexural and torsional effects. The bridge concrete slab was simulated by shell finite elements.

The proposed analysis methodology and the procedures presented in the design codes $[5,6]$ were used to evaluate the bridge fatigue response in terms of its structural service life. The main conclusions of this paper focused on alerting structural engineers to the possible distortions related to the bridge's service life when subjected to vehicle's dynamic actions.

\section{MATHEMATICAL MODEL}

\subsection{Bridge Deck Structural Model}

The structural model investigated in the present study corresponds to a composite (steel-concrete) highway bridge deck with straight axis, simple supported, spanning $13.0 \mathrm{~m}$ by $40.0 \mathrm{~m}$. The structural system is constituted of four composite girders and a $0.225 \mathrm{~m}$ thick concrete slab, as shown in Figures 1 to 4.

The steel sections used were welded wide flanges (WWF) made with a 350MPa yield stress steel grade and $485 \mathrm{MPa}$ ultimate strength. A $2.05 \times 105 \mathrm{MPa}$ Young's modulus was adopted for the steel beams. The concrete slab possesses a $25 \mathrm{MPa}$ specified compression strength and a $3.05 \times 104 \mathrm{MPa}$ Young's Modulus.

Two different cross sections were adopted for the longitudinal composite beams, as presented in Figure 4. Table 1 depicts the geometrical characteristics of the steel sections used in the structural model, as illustrated in Figures 1 to 4. 


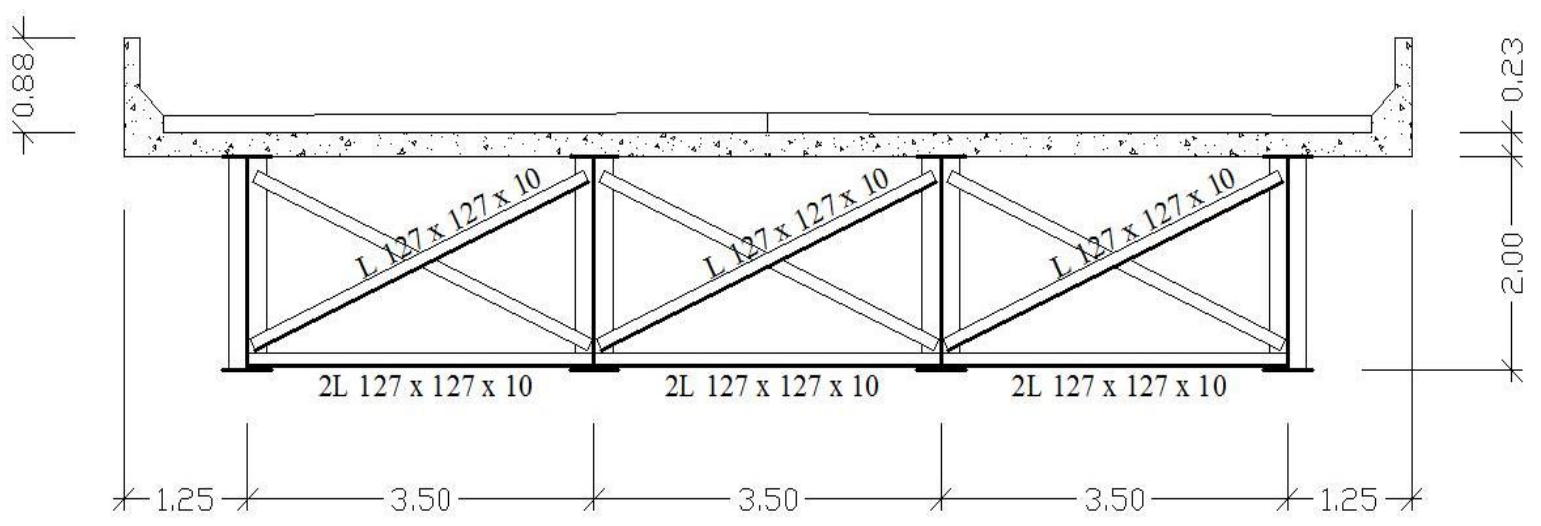

Figure 1. Bridge cross section.

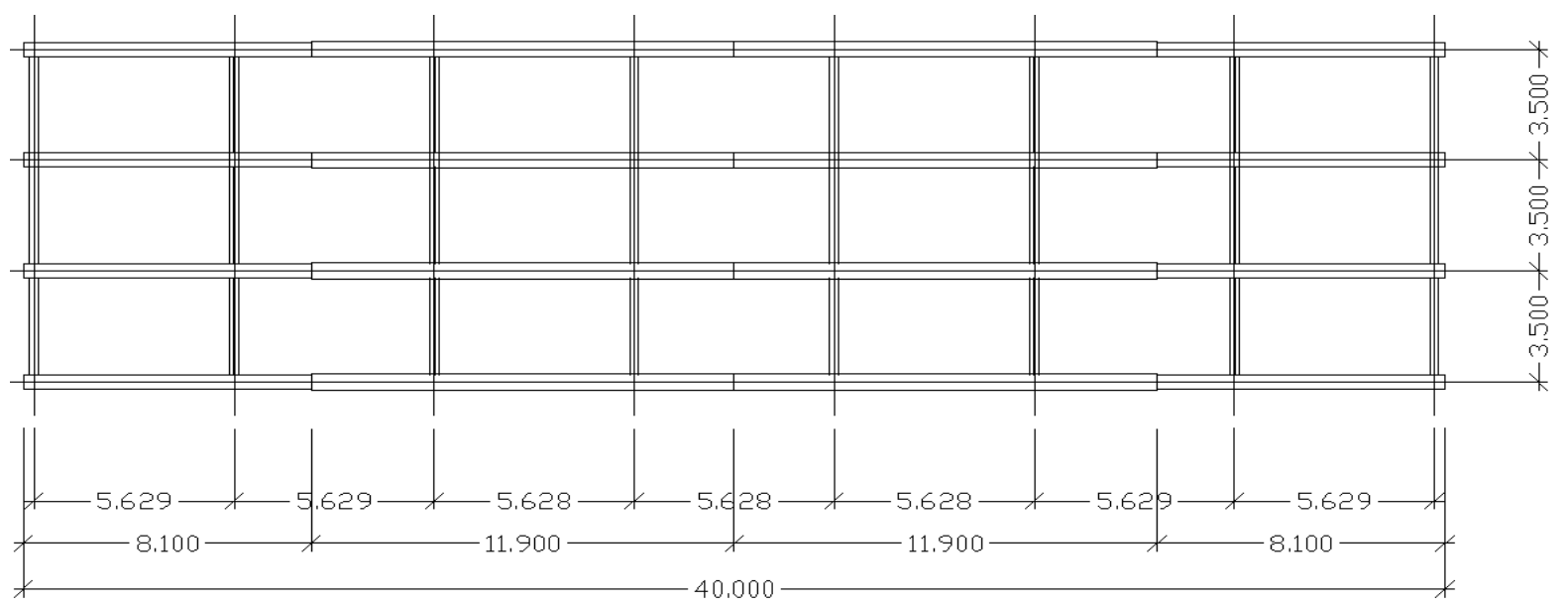

Figure 2. Bridge top view.
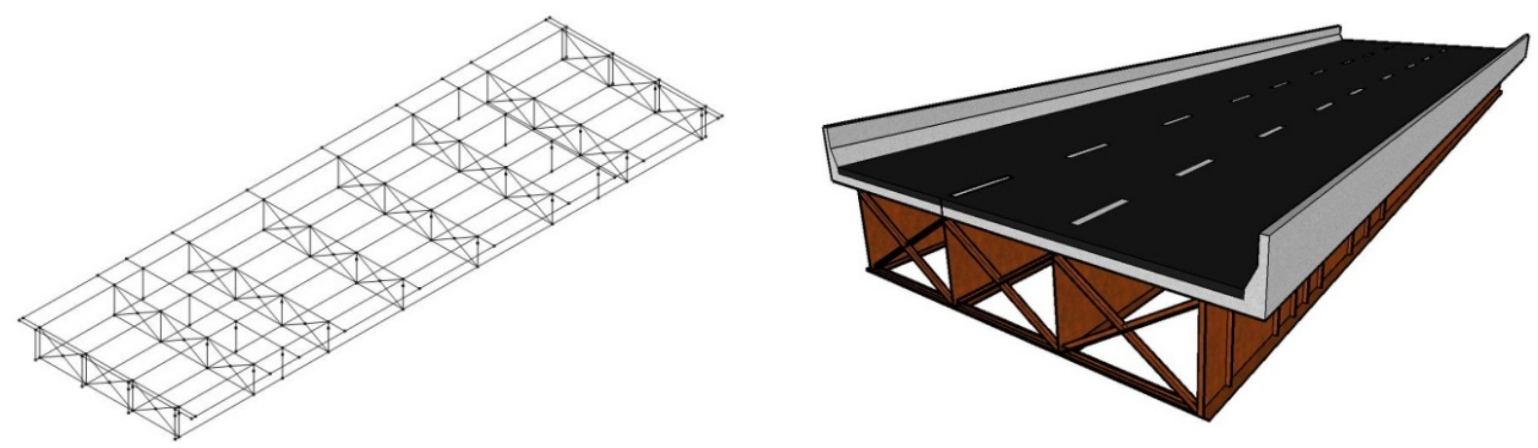

Figure 3. Three-dimensional bridge view.

\begin{tabular}{|c|c|c|c|}
\hline EXTREMITY & CENTRAL & CENTRAL & EXTREMITY \\
\hline
\end{tabular}

Figure 4. Different cross sections used along the bridge length. 
Table 1. Geometrical characteristics of the beam steel sections.

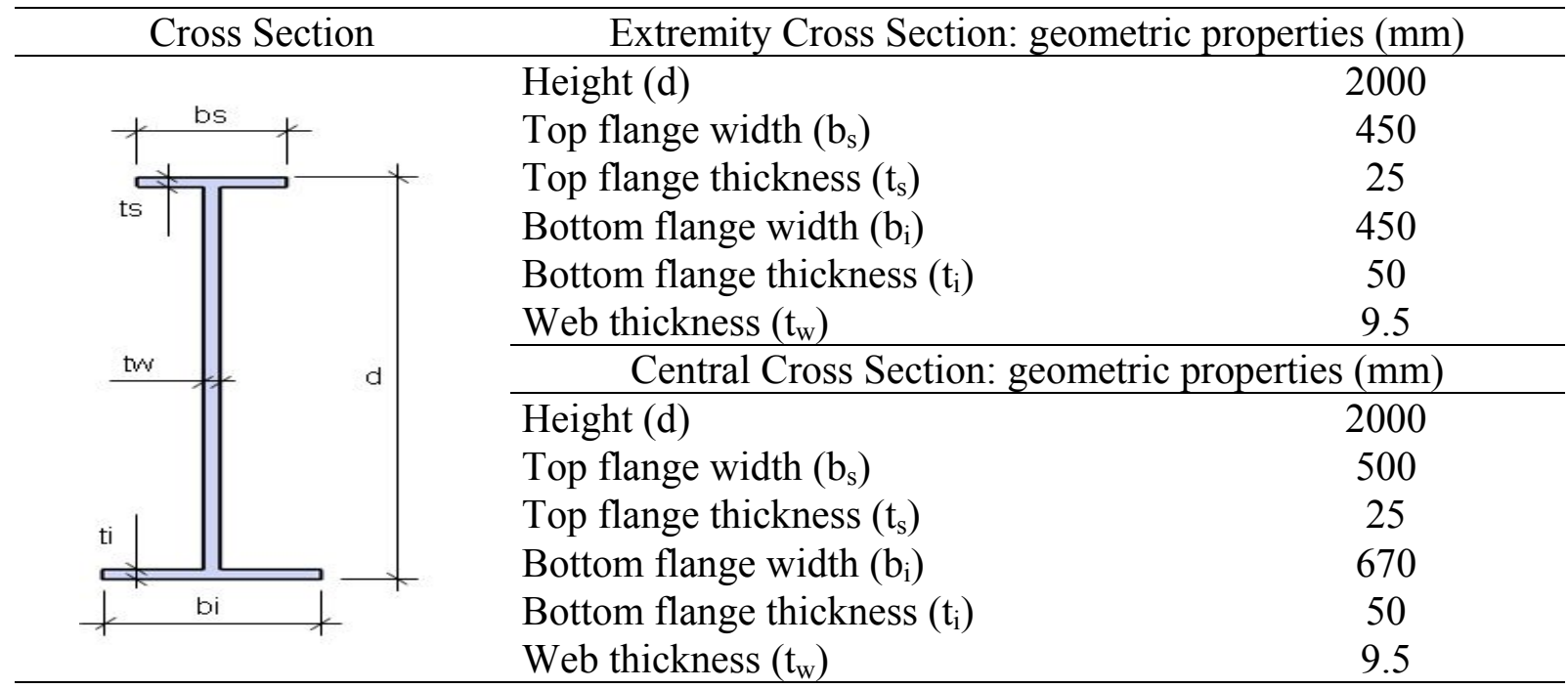

\subsection{Vehicle Model}

In this work, the adopted vehicle mathematical model was developed by Almeida $[8,9]$. This model is considered discrete and constituted by "mass-spring-damper" systems with three masses and a four freedom degree. The vehicle model was based on the NBR 7188 [10] vehicle "TB-12" and consists of a three masses model with four degrees of freedom (three translational and one rotational) and two axles to simulate each single vehicle, as presented in the Figure 5. Translational vertical displacements and rotational displacements are considered in the vehicle model.

Figure 5 illustrates this representation and uses the following notation: $\mathrm{u}_{\mathrm{v}}$, is the vehicle vertical displacement of the suspended mass; $\theta_{\mathrm{s}}$, is the vehicle rotational displacement related to the suspended mass; $\mathrm{u}_{1}$ and $\mathrm{u}_{2}$ are the vehicle vertical displacements of the nonsuspended mass; $\mathrm{m}_{\mathrm{s}}$ is the vehicle suspended mass; $\mathrm{m}_{\mathrm{ns}}$ is the vehicle $\mathrm{i}^{\text {th }}$ non-suspended mass (for each axle), respectively; $\mathrm{k}_{\mathrm{vs}}$ and $\mathrm{k}_{\mathrm{vp}}$ are the $\mathrm{i}^{\text {th }}$ stiffness coefficients related to vehicle suspension and tires (for each axle), respectively; $c_{v s}$ and $c_{v p}$ are $i^{\text {th }}$ the damping coefficients related to vehicle suspension and tires (for each axle), respectively.

The vehicle natural frequencies oscillating on rigid base (vertical motion), corresponding to the vehicle suspended mass (suspension system) and non-suspended mass degrees of freedom (tires), as presented in Figure 5, were made equal to $3.0 \mathrm{~Hz}$ and $20.0 \mathrm{~Hz}$, respectively $[8,9]$. However, the vehicle model has a lower natural frequency, associated to the vehicle suspended mass (suspension system) degree of freedom which is equal to $2.3 \mathrm{~Hz}$ (rotational motion).

The relative damping coefficient of the vehicles vibration mode with predominant movement of the vehicles suspended mass is assumed to be $\xi=0.1 \quad(\xi=10 \%)[8,9]$. The total mass used in this vehicle model is equal to $12 \mathrm{t}\left(\mathrm{m}_{\mathrm{s}}=10.667 \mathrm{~kg} ; \mathrm{m}_{\mathrm{ns} 1}=666.5 \mathrm{~kg}\right.$ and $\mathrm{m}_{\mathrm{ns} 1}=$ $666.5 \mathrm{~kg}$ ), corresponding to $120 \mathrm{kN}$ weight. The relation between the suspended mass and nonsuspended masses was considered equal the $8.0[8,9]$. 


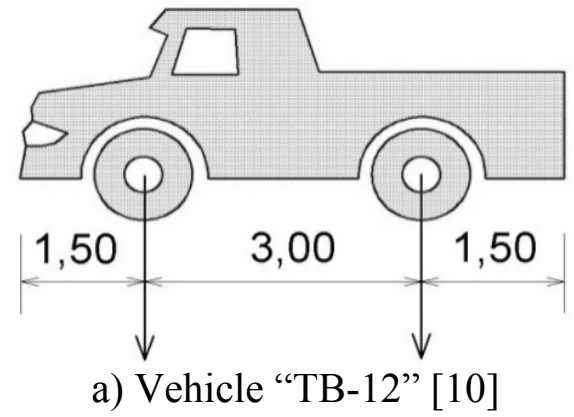

Figure 5: Vehicle model.

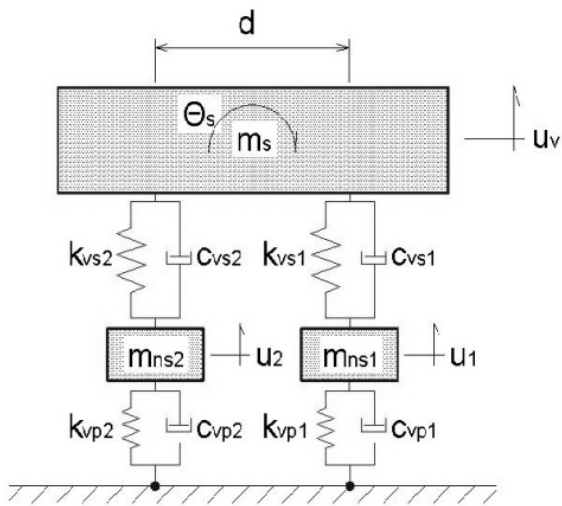

b) Mathematical model $[8,9]$

Figure 5 . Vel

\subsection{Semi-infinite Train of Vehicles}

The moving load is modelled by an infinite series of equal vehicles, regularly spaced, and running at constant velocity, $v$. If 1 is the distance between two successive vehicles and as these cars enter one by one into the bridge deck, it is created a time repeated movement variation governed by the frequency, $f_{t}=v / l$, associated with the movement of the vehicles on the bridge, which can be called traversing frequency [3].

After a certain time period, $\mathrm{t}_{1}$, denominated crossing period, the first vehicle in the train reaches the far end of the bridge and from this instant, on the total mass of the vehicles on the bridge remains practically constant. Under these conditions the bridge will soon reach a steady-state response situation, which includes repetition of maximum values directly related to the fatigue and the service life of the structure [3], as illustrated in Figures 6 to 8.

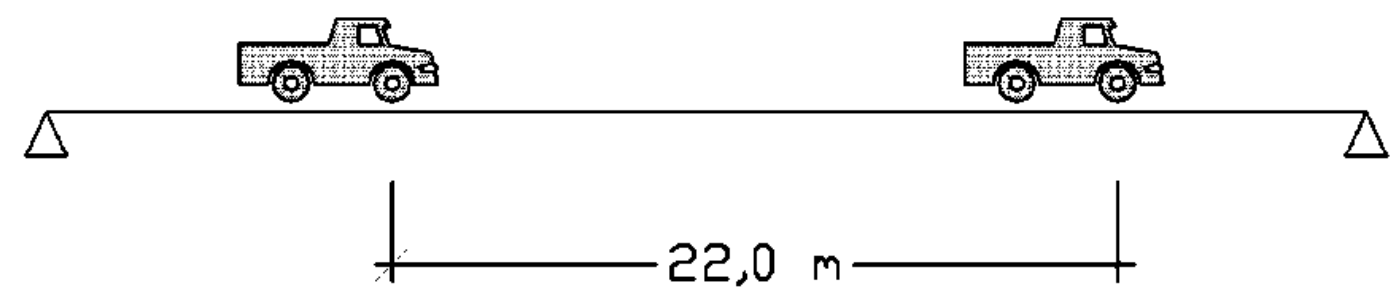

Figure 6: Two vehicles crossing the bridge: $v=80 \mathrm{~km} / \mathrm{h}$ and $1=22 \mathrm{~m}$ (Load Model I - LM-I).

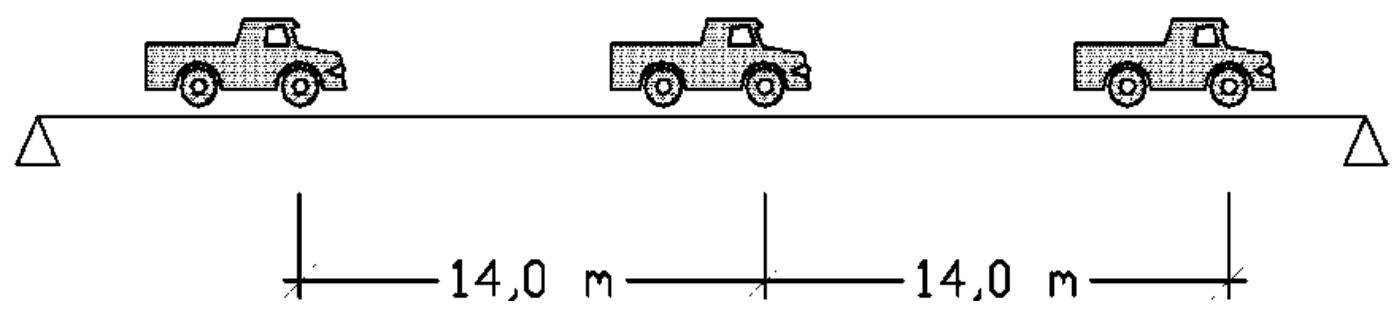

Figure 7: Three vehicles crossing the bridge: $v=80 \mathrm{~km} / \mathrm{h}$ and $1=14 \mathrm{~m}$ (Load Model II - LM-II). 


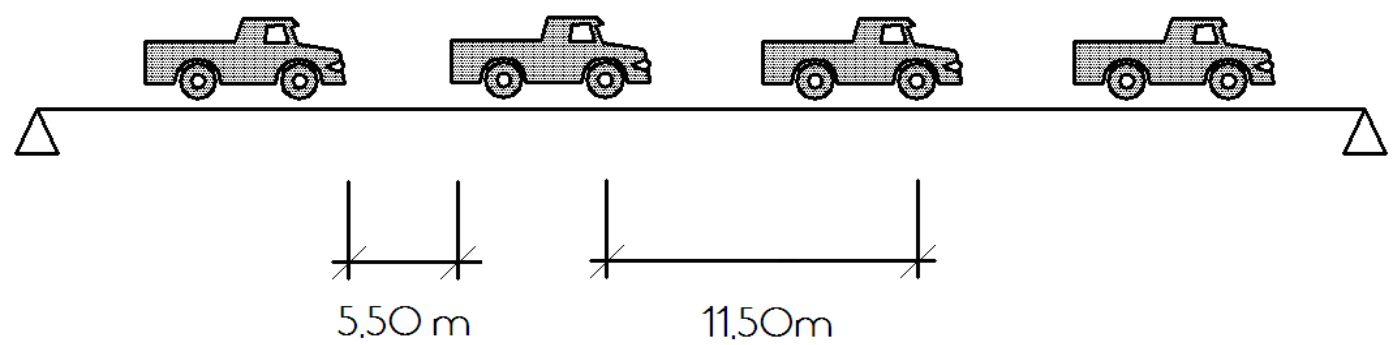

Figure 8: Four vehicles crossing the bridge: $v=60 \mathrm{~km} / \mathrm{h}$ and $1=11.50 \mathrm{~m}$

(Load Model III - LM-III).

\subsection{Structural Damping}

In this investigation, the structural damping was considered according to the Rayleigh proportional damping formulation [11]. The bridge structure damping matrix is defined by the parameters $\alpha$ and $\beta$, determined in function of the damping modal coefficient. According to this formulation [11], the structural system damping matrix [C] is proportional to the mass and stiffness matrix, as shown in Equation (1):

$$
[\mathrm{C}]=\alpha[\mathrm{M}]+\beta[\mathrm{K}]
$$

The expression above can be rewrite in terms of the modal damping coefficient and the natural frequency, leading to the Equation (2):

$$
\xi_{i}=\frac{\alpha}{2 \omega_{i}}+\frac{\beta \omega_{i}}{2}
$$

Where $\xi_{\mathrm{i}}$ is the modal damping coefficient and $\omega_{\mathrm{i}}$ is the natural frequency associated to the mode shape " $i$ ". Isolating the parameters $\alpha$ and $\beta$ of the Equation (2) for two natural frequencies, $\omega_{01}$ and $\omega_{02}$, adopted according to the relevance of the corresponding vibration mode for the structural system dynamical response, it can be written:

$$
\begin{aligned}
& \beta=\frac{2\left(\xi_{2} \omega_{02}-\xi_{1} \omega_{01}\right)}{\omega_{02} \omega_{02}-\omega_{01} \omega_{01}} \\
& \alpha=2 \xi_{1} \omega_{01}-\beta \omega_{01} \omega_{01}
\end{aligned}
$$

With two values of natural frequencies is possible to evaluate the parameters $\alpha$ and $\beta$ described before, see Equations (3) and (4). The reference frequencies $\omega_{01}$ and $\omega_{02}$ are generally taken as the extreme frequencies of the structure spectrum. In this paper the frequency $\omega_{01}$ adopted will be the structure fundamental frequency and the frequency $\omega_{02}$ considered will be the system second natural frequency. The modal damping coefficient adopted in this investigation is equal to $0.03(\xi=3 \%)[1-3]$. 


\section{FINITE ELEMENT MODELLING}

\subsection{Composite (Steel-Concrete) Bridge Finite Element Model}

The computational model, developed for the composite bridge dynamic analysis, adopted the usual mesh refinement techniques present in finite element method simulations implemented in the ANSYS program [7].

The beam steel sections were simulated by three-dimensional beam and shell finite elements. The beam web thickness was represented by shell finite elements (SHELL63 [7]). The beam top and bottom flange and the longitudinal and vertical stiffeners were simulated by three-dimensional beam elements (BEAM44 [7]), where flexural and torsion effects were considered. The bridge concrete slab was simulated by shell finite elements (SHELL63 [7]).

The computational model used rigid connections like "offsets" in order to guarantee the strain compatibility between plate elements (concrete slab) and three-dimensional beam elements (steel beams), simulating the composite (steel-concrete) highway bridge deck with full interaction.

The final computational model adopted used 4992 nodes, 2264 three-dimensional beam elements and 4324 shell elements, which resulted in a numeric model with 29952 degrees of freedom. In sequence, Figure 9 illustrates the composite bridge finite element model. Figure 10 illustrates this strategy considering the Load Model I (see Figure 6).

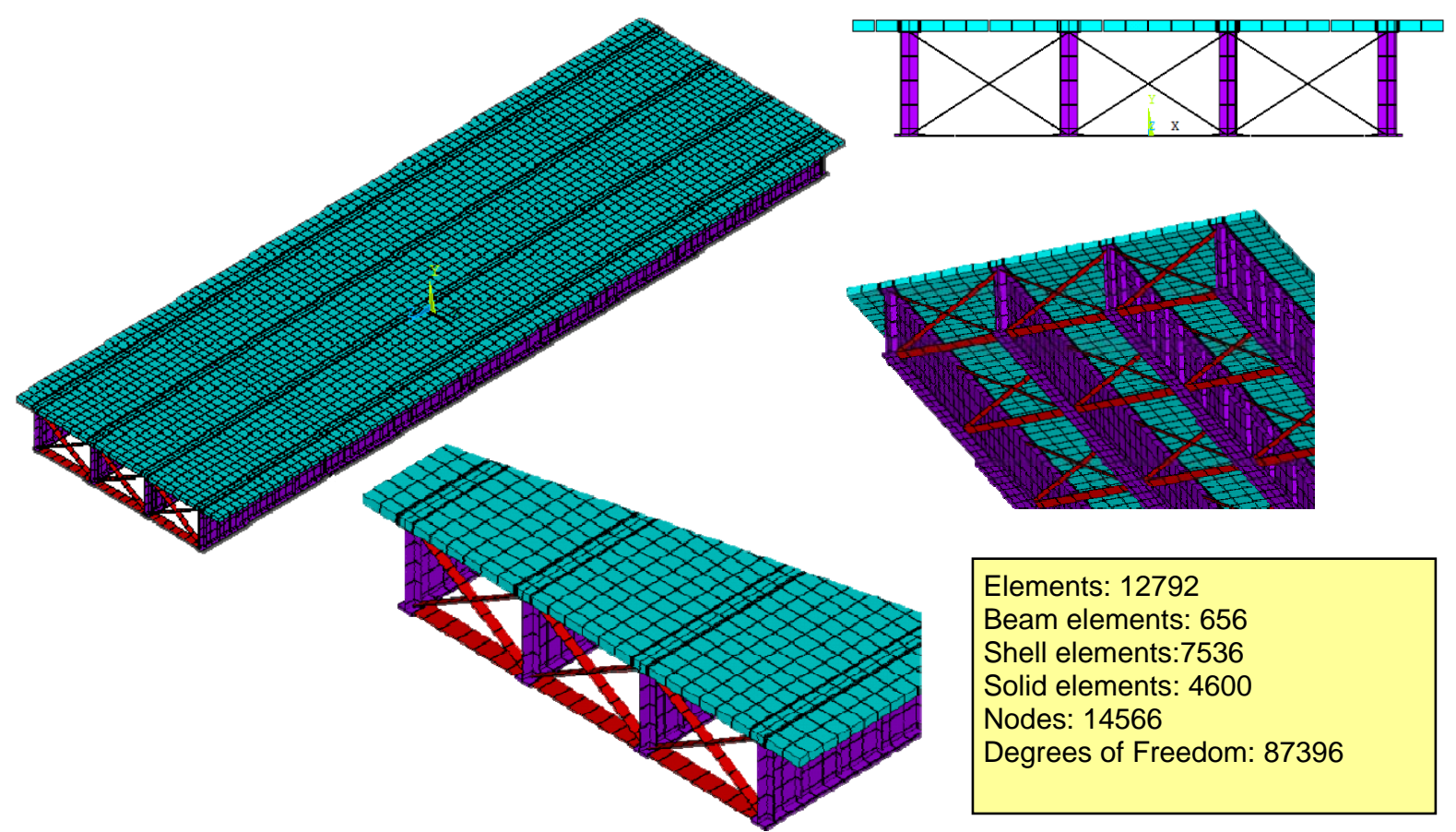

Figure 9. Composite (steel-concrete) highway bridge deck finite element model. 


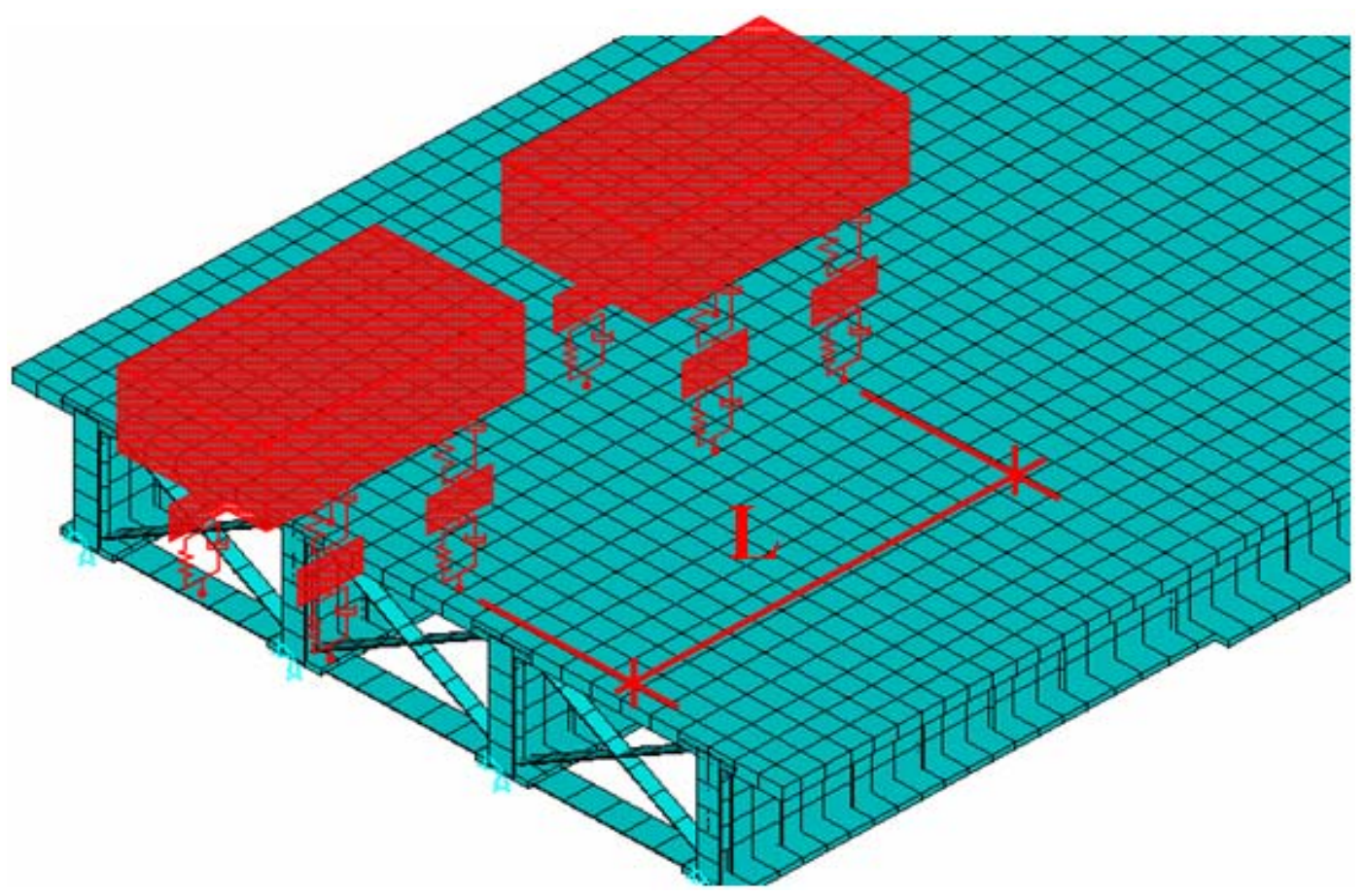

Figure 10. Vehicles crossing the investigated composite bridge.

\section{DYNAMIC ANALYSIS}

\subsection{Natural Frequencies and Vibration Modes}

The composite bridge natural frequencies were determined with the aid of the numerical simulations, as presented in Table 2 . The associated composite bridge vibration modes are shown in Figure 11.

It can be clearly noticed from Table 2 results, that there is a very good agreement between the finite elements frequencies values and the frequencies obtained by Silva [3] and Murray et al [12]. Such fact validates the numeric model here presented, as well as the results and conclusions obtained throughout this work.

Table 2. Composite bridge natural frequencies.

\begin{tabular}{|c|c|c|c|c|c|c|c|}
\hline \multicolumn{6}{|c|}{ Bridge natural frequencies: $\mathrm{f}_{0 \mathrm{i}}(\mathrm{Hz})$ - ANSYS [7] } & \multirow{2}{*}{$\begin{array}{c}\text { GDYNABT } \\
{[3]} \\
\mathrm{f}_{01}(\mathrm{~Hz})\end{array}$} & \multirow{2}{*}{$\begin{array}{c}\text { AISC } \\
{[12]} \\
\mathrm{f}_{01}(\mathrm{~Hz})\end{array}$} \\
\hline $\mathrm{f}_{01}$ & $\mathrm{f}_{02}$ & $\mathrm{f}_{03}$ & $\mathrm{f}_{04}$ & $\mathrm{f}_{05}$ & $\mathrm{f}_{06}$ & & \\
\hline 3.01 & 3.68 & 6.38 & 9.82 & 11.01 & 11.97 & 2.85 & 2.65 \\
\hline
\end{tabular}




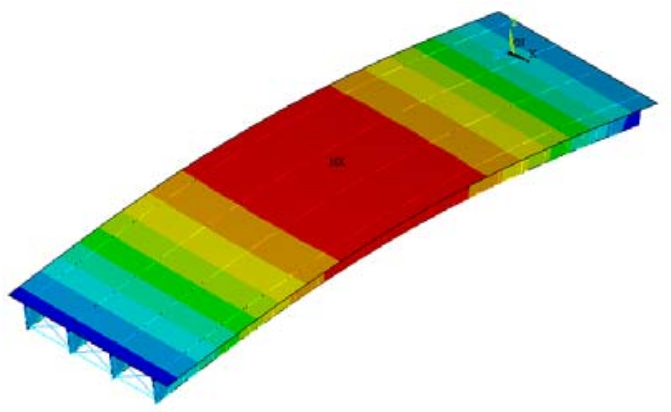

a) First vibration mode: $\mathrm{f}_{01}=3.01 \mathrm{~Hz}$.

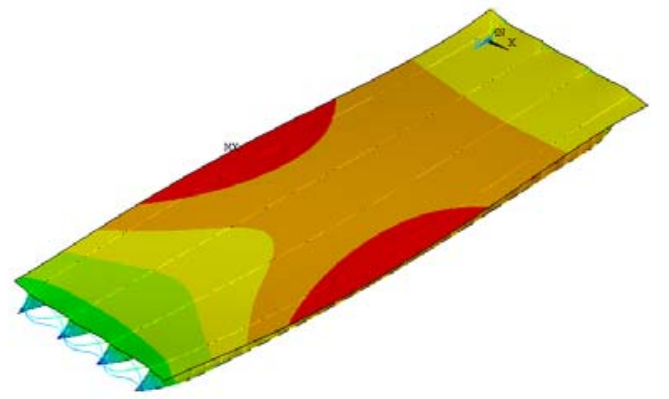

c) Third vibration mode: $\mathrm{f}_{03}=6.38 \mathrm{~Hz}$.

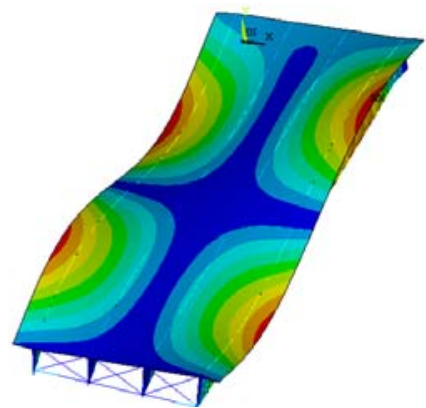

e) Fifth vibration mode: $\mathrm{f}_{05}=11.01 \mathrm{~Hz}$.

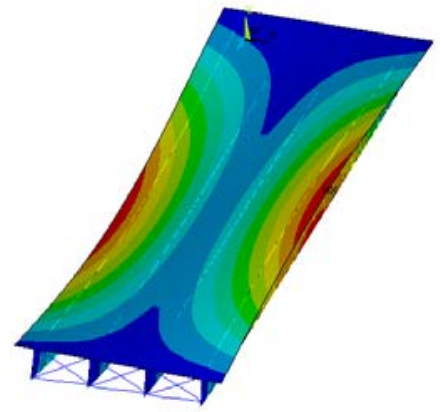

b) Second vibration mode: $\mathrm{f}_{02}=3.68 \mathrm{~Hz}$.

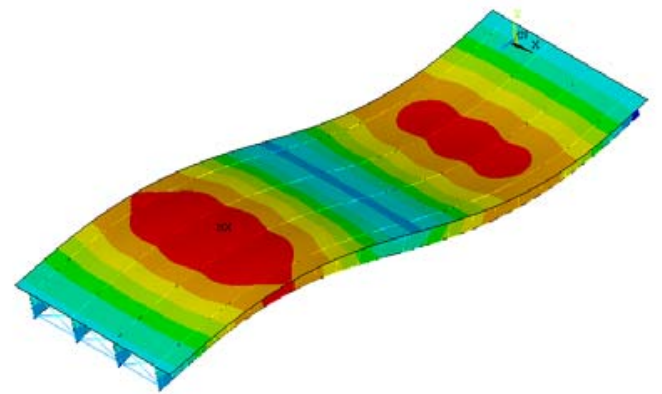

d) Fourth vibration mode: $\mathrm{f}_{04}=9.82 \mathrm{~Hz}$.

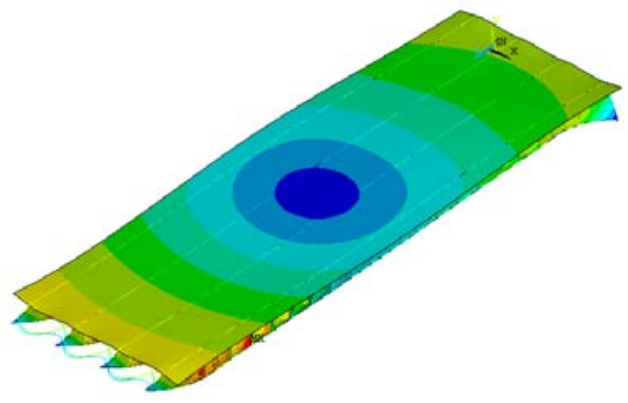

f) Sixth vibration mode: $\mathrm{f}_{06}=11.97 \mathrm{~Hz}$.

Figure 11. Composite bridge vibration modes.

\subsection{Composite Bridge Dynamic Response}

The dynamical analysis proceeded with the evaluation of the composite bridge dynamic response. Three loading cases were investigated: central track passage, lateral track passage and both lateral track passage, see Figures 12 and 13. Figures 14 and 15 illustrate the maximum stresses at the bottom flange of the composite beams, associated to flexural effects.

In general, the composite beams sections closer than dynamic loading application track presented higher stress values. In these situations the beams were subjected to higher impacts. It must be emphasized that the maximum stress values related to beam 1 (see Figure 13) were obtained when the LM-I (see Figure 6) was moving on the lateral track passage (see Figure 12). These higher values were expected on the bridge structural system due to the torsional vibration mode influence (see Figure 11). 


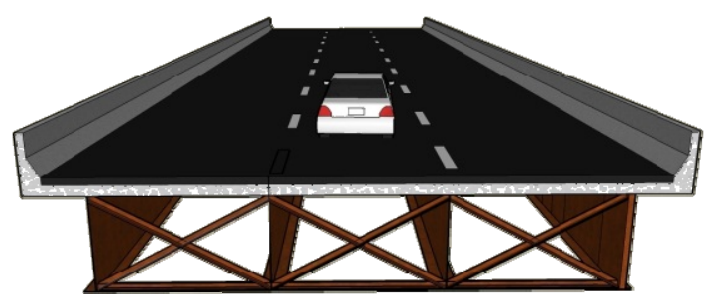

a) Central track passage.

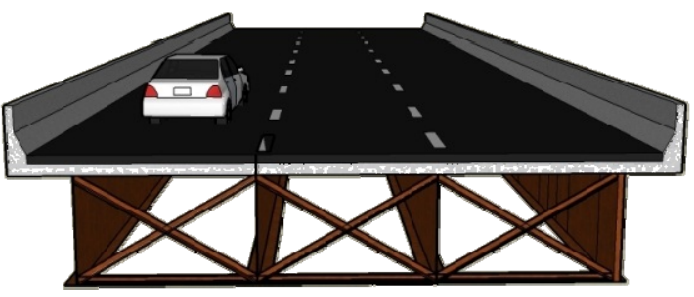

b) Lateral track passage.

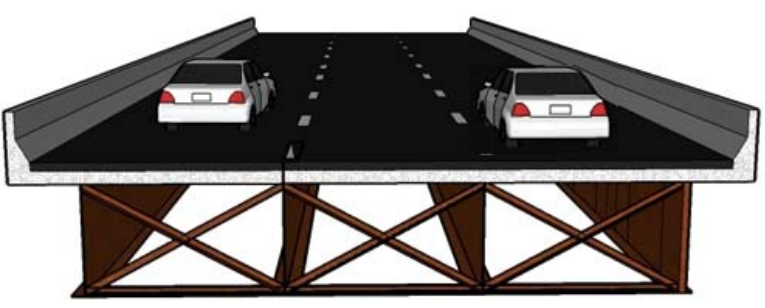

c) Both lateral track passage.

Figure 12. Investigated loading cases.

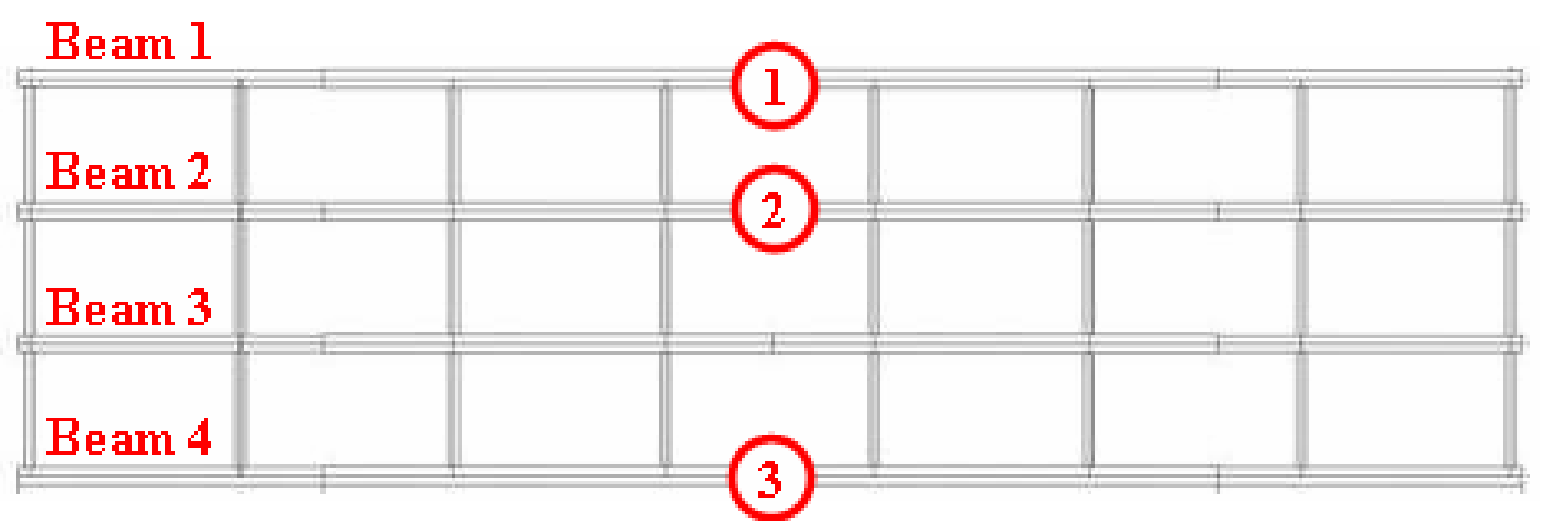

Figure 13. Location where the stresses were obtained on the bridge structure.

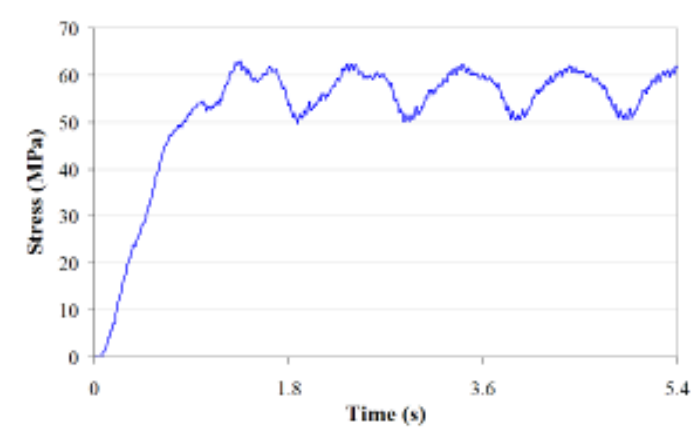

a) Beam 1 bottom flange.

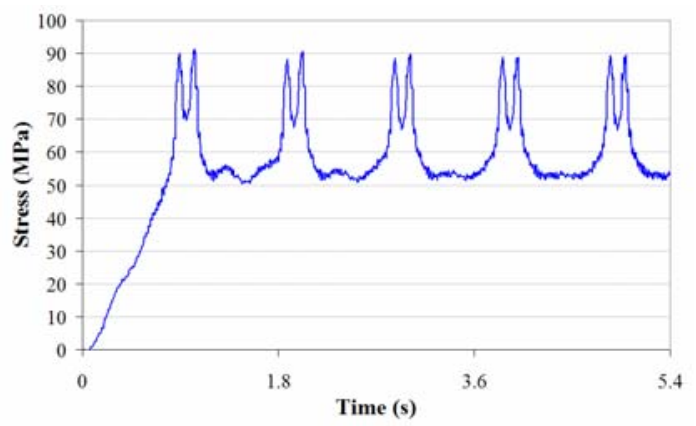

b) Beam 2 bottom flange.

Figure 14. Stresses due to the LM-I (see Figure 6). Load mobility effect. Central track passage. 


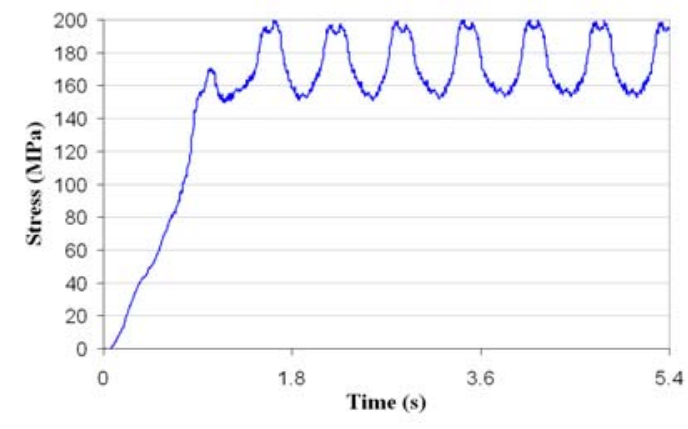

a) Beam 1 bottom flange.

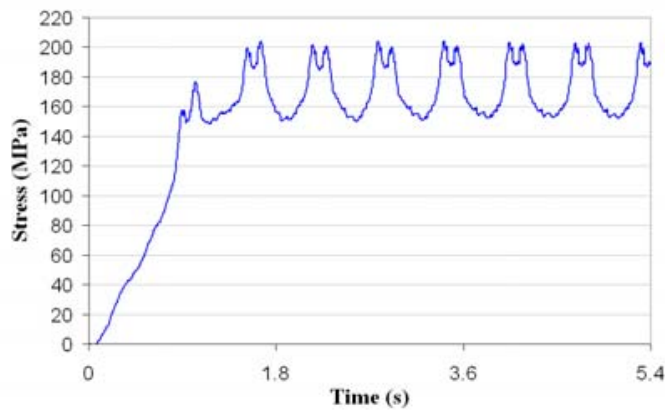

b) Beam 2 bottom flange.

Figure 15. Stresses due to the LM-II (see Figure 7).

Load mobility effect. Two lateral track passage.

On the other hand, the stress values corresponding to beam 4 (see Figure 13), opposite side of the lateral track convoy passage, were very small when compared with other composite beams. This is another important issue to the fatigue analysis due to the fact that the random nature of the dynamic loadings can make structural elements very loaded or even practically without loading along the time, causing an increase on the stress range.

\section{FATIGUE ASSESSMENT}

\subsection{Cycle Counting and Structural Element Fatigue Class}

The stress values obtained in the dynamic analysis, due to load mobility and irregular pavement surface effects, were used to evaluate the fatigue of the bridge determining the service life of the structure. However the analysis of the obtained results is very complex, with a lot of stress peaks and containing diversified values. Thus, the manual stress cycle counting becomes impossible. The peaks and valleys of the presented stress history graphs need to be counted. This investigation used the Rainflow method for stress cycle counting. In order to avoid the manual stress cycle counting a Matlab [13] routine was implemented and validated, based on results found by others authors [1-4].

Fatigue is a localized damage process of a component produced by cyclic loading. It is the result of the cumulative process consisting of crack initiation, propagation, and final fracture of a structural component. To determine the fatigue service life and cumulated damage it is necessary to obtain the stress ranges during the vehicles moving on the bridge structure.

The bridge steady state response, see Figures 14 and 15, was considered to obtain the maximum stress values due to vehicles traffic on the composite bridge deck. Based on these values, the Rainflow cycle counting was applied to determine the stress ranges. Each associated stress cycle was used proportionally with $2 \times 10^{6}$ cycles, which is the design code value for this analysis type [1-6]. These values associated with the S-N curves of each design code $[5,6]$ were used to obtain the cumulative damage and respectively the service life of each analysed structural element. It must be emphasized that each design code [5,6] considers different structural details classification, as presented in Table 3. 


\subsection{Composite Bridge Service Life}

In sequence of the analysis, Tables 4 to 12 illustrate the calculations of the composite bridge service life ( $\sigma_{\max }$ : maximum stresses and $\Delta \sigma_{\max }$ : stresses maximum variation) when LM-I, LM-II and LM-III (see Figures 6 to 8 ) were applied on the bridge structure. The vehicles were considered moving on the central and lateral track passage (see Figures 12 and 13).

Only the dynamic effects related to the load mobility were considered in this analysis. Tables 4 to 12 present the service life results for stress values associated with different structural elements (see Figures 12 and 13). The results were based on design code recommendations and specific S-N curves $[5,6]$.

Table 3. Structural details classification and fatigue class.

\begin{tabular}{|c|c|c|c|c|}
\hline \multirow{2}{*}{ Detail } & \multirow{2}{*}{ Picture } & \multirow{2}{*}{ Type } & \multicolumn{2}{|c|}{ Design code element fatigue class } \\
\hline & & & AASHTO [5] & EUROCODE 3 [6] \\
\hline 1 & & $\begin{array}{l}\text { Weld between } \\
\text { web and flange }\end{array}$ & B & 125 \\
\hline 2 & & $\begin{array}{l}\text { Cross section } \\
\text { union weld }\end{array}$ & $\mathrm{B}$ & 125 \\
\hline 3 & B & $\begin{array}{c}\text { Connectors } \\
\text { weld }\end{array}$ & $\mathrm{C}$ & 80 \\
\hline 4 & II0I & $\begin{array}{l}\text { Bottom stiff- } \\
\text { eners weld }\end{array}$ & $\mathrm{C}$ & 80 \\
\hline
\end{tabular}

Table 4. LM-I. Central track. Load mobility effect.

\begin{tabular}{lccccc}
\hline Detail & Beam & $\begin{array}{c}\sigma_{\max } \\
(\mathrm{MPa})\end{array}$ & $\begin{array}{c}\Delta \sigma_{\max } \\
(\mathrm{MPa})\end{array}$ & $\begin{array}{c}\text { AASTHO [5] } \\
75 \text { years* }\end{array}$ & $\begin{array}{c}\text { EUROCODE 3 [6] } \\
120 \text { years* }\end{array}$ \\
\hline \multirow{2}{*}{1 and 2 } & 1 & 63.03 & 12.00 & 19555.02 & 19854.81 \\
& 2 & 91.03 & 39.00 & 1065.71 & 1082.05 \\
& 4 & 63.03 & 12.00 & 19555.02 & 19854.81 \\
\hline \multirow{2}{*}{3 and 4 } & 1 & 63.03 & 12.00 & 7165.20 & 4987.30 \\
& 2 & 91.03 & 39.00 & 390.49 & 271.80 \\
\hline *Minimum bridge service life & & & & \\
\hline
\end{tabular}


Table 5. LM-I. Lateral track. Load mobility effect.

\begin{tabular}{lccccc}
\hline \multirow{2}{*}{ Detail } & Beam & $\begin{array}{c}\sigma_{\max } \\
(\mathrm{MPa})\end{array}$ & $\begin{array}{c}\Delta \sigma_{\max } \\
(\mathrm{MPa})\end{array}$ & $\begin{array}{c}\text { AASTHO [5] } \\
75 \text { years* }\end{array}$ & $\begin{array}{c}\text { EUROCODE 3 [6] } \\
120 \text { years* }\end{array}$ \\
\hline \multirow{3}{*}{1 and 2 } & 1 & 130.32 & 22.00 & 3707.85 & 3764.69 \\
& 2 & 99.92 & 46.00 & 675.57 & 685.93 \\
& 4 & 6.19 & 6.00 & 76441.65 & 77613.54 \\
\hline \multirow{3}{*}{3 and 4 } & 1 & 130.32 & 22.00 & 2492.03 & 1734.56 \\
& 2 & 99.92 & 46.00 & 247.54 & 172.30 \\
& 4 & 6.19 & 6.00 & 28009.15 & 19495.64 \\
\hline
\end{tabular}

*Minimum bridge service life

Table 6. LM-I. Both lateral tracks. Load mobility effect.

\begin{tabular}{cccccc}
\hline \multirow{2}{*}{ Detail } & Beam & $\begin{array}{c}\sigma_{\max } \\
(\mathrm{MPa})\end{array}$ & $\begin{array}{c}\Delta \sigma_{\max } \\
(\mathrm{MPa})\end{array}$ & $\begin{array}{c}\text { AASTHO [5] } \\
75 \text { years* }\end{array}$ & $\begin{array}{c}\text { EUROCODE 3 [6] } \\
120 \text { years* }\end{array}$ \\
\hline \multirow{2}{*}{ 1 and 2 } & 2 & 126.74 & 23.00 & 6793.52 & 6897.67 \\
& 4 & 126.74 & 23.00 & 6793.52 & 1479.65 \\
& 1 & 126.74 & 23.00 & 2489.23 & 6897.67 \\
3 3 and 4 & 2 & 132.46 & 29.00 & 533.98 & 1732.62 \\
& 4 & 126.74 & 23.00 & 2489.23 & 1732.62 \\
\hline *Minimum bridge service life & & &
\end{tabular}

*Minimum bridge service life

Table 7. LM-II. Central track. Load mobility effect.

\begin{tabular}{cccccc}
\hline Detail & Beam & $\begin{array}{c}\sigma_{\max } \\
(\mathrm{MPa})\end{array}$ & $\begin{array}{c}\Delta \sigma_{\max } \\
(\mathrm{MPa})\end{array}$ & $\begin{array}{c}\text { AASTHO [5] } \\
75 \text { years* }\end{array}$ & $\begin{array}{c}\text { EUROCODE 3 [6] } \\
120 \text { years* }^{*}\end{array}$ \\
\hline \multirow{3}{*}{1 and 2 } & 1 & 96.59 & 11.00 & 14154.66 & 14371.66 \\
& 2 & 127.95 & 52.00 & 567.44 & 576.14 \\
& 4 & 96.59 & 11.00 & 14154.66 & 14371.66 \\
\hline \multirow{3}{*}{ and 4 } & 1 & 96.59 & 11.00 & 5186.44 & 3610.00 \\
& 2 & 127.95 & 52.00 & 207.92 & 144.72 \\
& 4 & 96.59 & 11.00 & 5186.44 & 3610.00 \\
\hline
\end{tabular}

*Minimum bridge service life 
Table 8. LM-II. Lateral track. Load mobility effect.

\begin{tabular}{lccccc}
\hline Detail & Beam & $\begin{array}{c}\sigma_{\max } \\
(\mathrm{MPa})\end{array}$ & $\begin{array}{c}\Delta \sigma_{\max } \\
(\mathrm{MPa})\end{array}$ & $\begin{array}{c}\text { AASTHO [5] } \\
75 \text { years* }\end{array}$ & $\begin{array}{c}\text { EUROCODE 3 [6] } \\
120 \text { years* }\end{array}$ \\
\hline \multirow{3}{*}{1 and 2 } & 1 & 203.67 & 47.00 & 472.34 & 479.58 \\
& 2 & 147.93 & 46.00 & 266.39 & 270.47 \\
& 4 & 7.51 & 4.00 & 299921.05 & 304519.00 \\
\hline \multirow{3}{*}{3 and 4 } & 1 & 203.67 & 47.00 & 173.07 & 120.47 \\
& 2 & 147.93 & 46.00 & 97.61 & $\mathbf{6 7 . 9 4}$ \\
& 4 & 7.51 & 4.00 & 109894.74 & 76491.72 \\
\hline *Minimum bridge service life & & &
\end{tabular}

Table 9. LM-II. Both lateral tracks. Load mobility effect.

\begin{tabular}{lccccc}
\hline Detail & Beam & $\begin{array}{c}\sigma_{\max } \\
(\mathrm{MPa})\end{array}$ & $\begin{array}{c}\Delta \sigma_{\max } \\
(\mathrm{MPa})\end{array}$ & $\begin{array}{c}\text { AASTHO [5] } \\
75 \text { years* }\end{array}$ & $\begin{array}{c}\text { EUROCODE 3 [6] } \\
120 \text { years* }\end{array}$ \\
\hline \multirow{3}{*}{1 and 2 } & 1 & 200.36 & 48.00 & 406.27 & 412.49 \\
& 2 & 204.28 & 53.00 & 167.27 & 169.83 \\
& 4 & 200.36 & 48.00 & 406.27 & 412.49 \\
\hline \multirow{3}{*}{ and 4 } & 1 & 200.36 & 48.00 & 148.86 & $\mathbf{1 0 3 . 6 1}$ \\
& 2 & 204.28 & 53.00 & $\mathbf{6 1 . 2 9}$ & $\mathbf{4 2 . 6 6}$ \\
& 4 & 200.36 & 48.00 & 148.86 & $\mathbf{1 0 3 . 6 1}$ \\
\hline
\end{tabular}

*Minimum bridge service life

Table 10. LM-III. Central track. Load mobility effect.

\begin{tabular}{lccccc}
\hline \multirow{2}{*}{ Detail } & Beam & $\begin{array}{c}\sigma_{\max } \\
(\mathrm{MPa})\end{array}$ & $\begin{array}{c}\Delta \sigma_{\max } \\
(\mathrm{MPa})\end{array}$ & $\begin{array}{c}\text { BASTHO [5] } \\
75 \text { years* }\end{array}$ & $\begin{array}{c}\text { EUROCODE 3 [6] } \\
120 \text { years* }\end{array}$ \\
\hline \multirow{3}{*}{1 and 2 } & 2 & 29.67 & 35.00 & 296.20 & 300.74 \\
& 4 & 27.28 & 35.00 & 296.20 & $\mathbf{7 2 . 9 3}$ \\
& 1 & 27.28 & 35.00 & 108.53 & 300.74 \\
\hline \multirow{3}{*}{3 and 4 } & 2 & 29.67 & 53.00 & $\mathbf{2 6 . 3 2}$ & $\mathbf{7 5 . 5 4}$ \\
& 4 & 27.28 & 35.00 & 108.53 & $\mathbf{1 8 . 3 2}$ \\
\hline
\end{tabular}


Table 11. LM-III. Lateral track. Load mobility effect.

\begin{tabular}{lccccc}
\hline Detail & Beam & $\begin{array}{c}\sigma_{\max } \\
(\mathrm{MPa})\end{array}$ & $\begin{array}{c}\Delta \sigma_{\max } \\
(\mathrm{MPa})\end{array}$ & $\begin{array}{c}\text { BASTHO [5] } \\
75 \text { years* }\end{array}$ & $\begin{array}{c}\text { EUROCODE 3 [6] } \\
120 \text { years* }\end{array}$ \\
\hline \multirow{3}{*}{1 and 2 } & 2 & 28.50 & 46.00 & 274.98 & $\mathbf{1 0 9 . 1 7}$ \\
& 4 & 20.22 & 11.00 & 9157.79 & 279.20 \\
\hline \multirow{3}{*}{3 and 4 } & 1 & 46.21 & 43.00 & $\mathbf{3 9 . 4 0}$ & 9298.18 \\
& 2 & 28.50 & 46.00 & 100.76 & $\mathbf{2 7 . 4 2}$ \\
& 4 & 20.22 & 11.00 & 3355.53 & $\mathbf{7 0 . 1 3}$ \\
\hline
\end{tabular}

*Minimum bridge service life

Table 12. LM-III. Both lateral tracks. Load mobility effect.

\begin{tabular}{cccccc}
\hline Detail & Beam & $\begin{array}{c}\sigma_{\max } \\
(\mathrm{MPa})\end{array}$ & $\begin{array}{c}\Delta \sigma_{\max } \\
(\mathrm{MPa})\end{array}$ & $\begin{array}{c}\text { BASTHO [5] } \\
75 \text { years* }\end{array}$ & $\begin{array}{c}\text { EUROCODE 3 [6] } \\
120 \text { years* }\end{array}$ \\
\hline \multirow{3}{*}{1 and 2 } & 1 & 21.29 & 40.00 & 124.68 & 126.59 \\
& 2 & 39.33 & 52.00 & 173.06 & 175.72 \\
& 4 & 43.10 & 52.00 & 133.48 & 135.53 \\
\hline \multirow{3}{*}{3 and 4 } & 1 & 21.29 & 40.00 & $\mathbf{4 5 . 6 8}$ & $\mathbf{3 1 . 8 0}$ \\
& 2 & 39.33 & 52.00 & $\mathbf{6 3 . 2 5}$ & $\mathbf{4 4 . 0 3}$ \\
& 4 & 43.10 & 52.00 & $\mathbf{4 8 . 9 1}$ & $\mathbf{3 4 . 0 4}$ \\
\hline
\end{tabular}

*Minimum bridge service life

The stress values obtained in the dynamic analysis due to load mobility was used to evaluate the fatigue performance of the investigated composite bridge measured in terms of its service life. However, the analysis of the results is very complex, with numerous stress peaks of diversified magnitudes.

Thus, manual stress cycle counting is, for these structures, an impossible task. This way, the present investigation adopts the Rainflow method for stress cycle counting. In order to avoid the manual stress cycle counting approach, a Matlab [13] routine was developed, implemented and validated, based on results presented by others authors [1-4].

The results presented in Tables 4 to 12, related to the three loading cases LM-I, d LMII and LM-III (see Figures 6 to 8), indicated that the investigated composite (steel-concrete) highway bridge will perform safely with an acceptable probability that indicates that a failure by fatigue cracking will not occur.

In fact, in most of the analysed cases, the composite bridge service life values were higher than those proposed by the design codes [5,6], ensuring that the members, connections and joints subjected to dynamic actions related to the load mobility effects will not failure by fatigue cracking. 
However, when the lateral track path (LM-II, see Figures 7 and 12) and two simultaneous lateral track paths (LM-III, see Figures 8 and 12) dynamic actions were applied on the investigated structural system, it was concluded that the service life values proposed by the design codes [5,6] were surpassed in some specific situations, see Tables 8 to 12 .

Another important aspect is the influence of the dynamic load position. In this investigation, when the loading situation was associated to the convoy of vehicles moving on the bridge lateral track passage the stress values and also stress ranges were higher than those obtained when compared to those provided by vehicles moving on the bridge central track passage. This conclusion emphasizes the importance to consider the contribution of torsional vibrations modes in the composite (steel-concrete) highway bridge dynamical analysis.

It was observed that when the vehicles convoy is moving on the bridge left lateral track, some structural elements, near the dynamic loading position, presented high stress values, while the other structural elements presented small stress values. This alternation in the stress values produced a significant influence on the stress range.

\section{FINAL CONSIDERATIONS}

In this investigation, an analysis methodology was presented to evaluate the fatigue of the steel and composite highway bridges in terms of the structural system service life. The composite bridge service life results corroborated the importance of considering the roughness of the pavement surface and other design parameters like: floor thickness, structural damping and beam cross section geometrical properties in the bridge dynamic and fatigue analysis.

The analysis methodology considered a vehicle-structure mathematical model, which includes the interaction between their dynamical properties and is developed to evaluate the vehicle-structure response running in the time domain. It must be emphasized that the results obtained in the present investigation are applied mainly for heavy vehicles moving over composite (steel-concrete) highway bridge decks.

The investigated composite (steel-concrete) highway bridge will perform safely with an acceptable probability that indicates that failure by fatigue cracking will not occur. The structural system service life values were higher than those proposed by the design codes $[5,6]$, ensuring that the members, connections and joints will not failure by fatigue cracking.

However, when the dynamic actions related to the vehicles moving on the bridge lateral track path and two simultaneous lateral track paths were applied on the bridge structure, it was observed that the service life values proposed by the design codes $[5,6]$ were surpassed in some specific situations.

On the other hand, when the loading situation was associated with the vehicles moving on the bridge lateral track path, the stress values and stress ranges were higher than those obtained with the results related to the case of vehicles moving on the bridge central track path. It could also be concluded that the contribution of torsional vibration modes presented influence on the composite (steel-concrete) highway bridge dynamic and fatigue analysis. 
The analysis methodology presented in this paper is general and is the author intention to use this solution strategy on other highway bridge types such as: multigirder bridges, continuous multigirder bridges, cable-stayed bridges, slant-legged rigid-frame bridges, and so forth. The fatigue problem is certainly much more complicated and is influenced by several highway bridge types. Further research in this area is currently being carried out.

\section{Acknowledgements}

The authors gratefully acknowledge the financial support for this work provided by the Brazilian Science Foundations CAPES, CNPq and FAPERJ.

\section{REFERENCES}

[1] Leitão, F.N., "Fatigue Analysis of Composite Highway Bridges", MSc Dissertation (In Portuguese). Civil Engineering Post-graduate Programme, PGECIV. State University of Rio de Janeiro, UERJ, Rio de Janeiro, Brazil, 2009.

[2] Leitão, F.N., Silva, J.G.S. da, Andrade, S.A.L. de, Vellasco, P.C.G. da S., Lima, L.R.O. de, "Composite (Steel-Concrete) Highway Bridge Fatigue Assessment", Journal of Constructional Steel Research, 67 (1), 14-24, 2011.

[3] Silva, J.G.S. da, "Dynamical Performance of Highway Bridge Decks with Irregular Pavement Surface”. Computer \& Structures, 82 (11-12), 871-881, 2004.

[4] Pravia, Z.M.C., "Steel Bridge Structures with Crack Stability". DSc Thesis (In Portuguese). COPPE/UFRJ, Rio de Janeiro, RJ, Brazil, 2003.

[5] AASHTO. LRFD Bridge Design Specifications. American Association of State High-way and Transportation Officials, Washington, USA, 2005.

[6] EUROCODE 3. Design of Steel Structures. European Committee for Standardisation. Bruxelas, 2003.

[7] ANSYS Swanson Analysis Systems, Inc., P. O. Box 65, Johnson Road, Houston, PA, 15342-0065. Release 11.0, SP1 UP20070830, ANSYS, Inc. is a UL registered ISO 9001:2000 Company. Products ANSYS Academic Research, Using FLEXIm v10.8.0.7 build 26147, Customer 00489194, 2007.

[8] Almeida, R. S. de, "Vibration Analysis of Highway Bridges due Vehicle Traffic on Roughness Pavement Surface”. MSc Dissertation (In Portuguese). Civil Engineering Postgraduate Programme, PGECIV, State University of Rio de Janeiro, UERJ, Rio de Janeiro, Brazil, 2006. 
[9] Almeida, R. S. de and Silva, J.G.S. da, "A Stochastic Modelling of the Dynamical Response of Highway Bridge Decks Under Traffic Loads". ECCM 2006 - III European Conference on Computational Mechanics, 2006.

[10] NBR 7188. Carga Móvel em Ponte Rodoviária e Passarela de Pedestre. Associação Brasileira de Normas Técnicas, Rio de Janeiro/RJ, Brazil, 1984.

[11] Clough, R.W. and Penzien J., "Dynamics of Structures", McGraw-Hill, 634 pages, 1993.

[12] Murray, T.M., Allen, D.E. and Ungar, E.E., "Floor Vibration due to Human Activity", Steel Design Guide Series, AISC, Chicago, USA, 2003.

[13] MATLAB ${ }^{\circledR}$ - The Language of Technical Computing, Release 7.0, 2007. 